\title{
Al-P-Zn (Aluminum-Phosphorus-Zinc)
}

\section{Raghavan}

An isothermal section at $450{ }^{\circ} \mathrm{C}$ was determined for this ternary system by [2009Tu]. The diagram was also calculated by thermodynamic modeling.

\section{Binary Systems}

The Al-P phase diagram [Massalski2] contains one stoichiometric compound AlP (B3, ZnS (sphalerite)-type cubic). The Al-Zn phase diagram [Massalski2] contains no intermediate phases. A miscibility gap occurs in the Al-based face centered cubic (fcc) solid solution below $351^{\circ} \mathrm{C}$, where the fcc phase splits into $(\mathrm{Al})^{\prime}$ and $(\mathrm{Al})^{\prime \prime}$. The monotectoid reaction $(\mathrm{Al})^{\prime \prime} \leftrightarrow(\mathrm{Al})^{\prime}+(\mathrm{Zn})$ follows at $277{ }^{\circ} \mathrm{C}$. The intermediate compounds in the P-Zn system [Massalski2, 2009Tu] are: $\beta \mathrm{Zn}_{3} \mathrm{P}_{2}$ (cubic), $\alpha \mathrm{Zn}_{3} \mathrm{P}_{2}\left(D 5_{9}\right.$, $\mathrm{Zn}_{3} \mathrm{P}_{2}$-type tetragonal), $\beta \mathrm{ZnP}_{2}\left(\mathrm{ZnAs}_{2}\right.$-type monoclinic) and $\alpha \mathrm{ZnP}_{2}\left(\mathrm{ZnP}_{2}\right.$-type tetragonal).

\section{Ternary Isothermal Section}

With starting metals of $99.99 \%$ purity, [2009Tu] melted eight alloys in evacuated tubes. The alloys were given a final anneal at $450{ }^{\circ} \mathrm{C}$ for $21 \mathrm{~d}$ and quenched in water. The phase equilibria were studied with x-ray powder diffraction and scanning electron microscope equipped with energy dispersive $\mathrm{x}$-ray analyzer. The measured phase compositions were listed [2009Tu].

In the thermodynamic modeling, [2009Tu] used the parameters optimized by [1993Mey] for the Al-Zn system and carried out their own optimization for the Al-P and P-Zn systems. The ternary isothermal section at $450{ }^{\circ} \mathrm{C}$ was calculated from the binary interaction parameters. The computed isothermal section at $450{ }^{\circ} \mathrm{C}$ is shown in Fig. 1, along with the experimental data points of [2009Tu]. The composition ranges of $(\mathrm{Al})$ and the liquid phase along

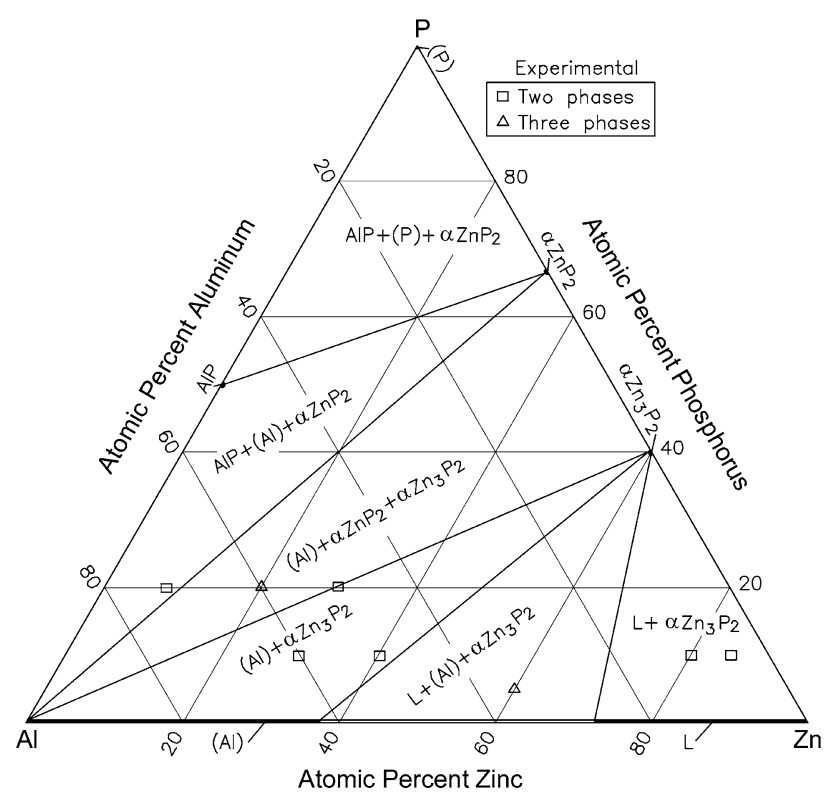

Fig. 1 Al-P-Zn computed isothermal section at $450{ }^{\circ} \mathrm{C}$ [2009Tu]. Narrow two-phase regions are omitted

the $\mathrm{Al}-\mathrm{Zn}$ side are as given in the computed equilibria. No ternary solubility is seen in the binary compounds. No ternary phase was detected in the experiments.

\section{References}

1993Mey: S. An Mey, Reevaluation of the Al-Zn System, Z. Metallkd., 1993, 84(7), p 451-455

2009Tu: H. Tu, F. Yin, X. Su, Y. Liu, and X. Wang, Experimental Investigation and Thermodynamic Modeling of the Al-P-Zn Ternary System, CALPHAD, 2009, 33, p 755-760 